\title{
High glucose increases LPS-induced DC apoptosis through modulation of ERK1/2, AKT and Bax/Bcl-2
}

\author{
Mei Feng ${ }^{1}$, Juan Li ${ }^{2}$ J Jun Wang ${ }^{3}$, Chunyan Ma ${ }^{1}$, Yulian Jiao ${ }^{1}$, Yan Wang ${ }^{4}$, Jie Zhang ${ }^{1}$, Qiuying Sun ${ }^{5}$, Ying Ju ${ }^{6}$, \\ Ling $\mathrm{GaO}^{1^{*}}$ and Yueran Zhao ${ }^{1 *}$
}

\begin{abstract}
Background: This study investigates the effect of glucose on the LPS-induced apoptosis of dendritic cells in the intestinal tract of mice and the dendritic cell line DC2.4.

Methods: Flow cytometry was used to detect dendritic cell apoptosis both in vivo and in vitro. Hoechst 33258 staining was used to detect the morphological changes characteristic of apoptotic nuclei. Expression of apoptosis related proteins was investigated by western blot analysis and immunohistochemistry.

Results: Pretreatment with a high concentration of glucose increased apoptosis of LPS-treated dendritic cells both in vivo and in vitro at $24 \mathrm{~h}$. No effect was evident at the earlier time points of $15 \mathrm{~min}$ and $6 \mathrm{~h}$ in vitro. Furthermore, at 24 hours the expression of the survival proteins AKT, ERK and BCl-2 was decreased, while the expression of the proapoptotic protein Bax was increased. AKT, ERK, BCl-2 and Bax were mainly located in the cytoplasm by immunohistochemistry.

Conclusions: These results suggest that high glucose concentrations might prime dendritic cells for apoptosis induced by LPS in the intestinal tract through upregulating the expression of Bax and downregulating the expression of AKT, ERK and BCl-2. Therefore, this study may give clues to understanding the immunological mechanism behind gastrointestinal complications in diabetes mellitus.
\end{abstract}

Keywords: Dendritic cell, Apoptosis, Diabetes mellitus, Glucose, Gastrointestinal complications diabetes

\section{Background}

There were approximately 285 million adults with diabetes worldwide in 2010, and the number has continued to increase [1]. Diabetes can lead to premature death and has various complications associated with it including blindness, peripheral neuropathy, renal disease and cardiovascular diseases. The complications of diabetes mellitus are accelerated in people who also have poorly controlled blood sugar levels. Other risk factors for complications include smoking, elevated cholesterol levels, obesity, high blood pressure and lack of regular exercise [2]. It has also been reported that high glucose levels induce immune cell apoptosis [3]. Raab et al. additionally showed that high energy substrates in the diet increased apoptosis in the intestinal epithelium [4].

\footnotetext{
*Correspondence: yanshu_2004@163.com; liuyr2011@hotmail.com ${ }^{1}$ Central Laboratory, Shandong Provincial Hospital affiliated to Shandong University, Jinan, China

Full list of author information is available at the end of the article
}

The immune system is pivotal in mediating interactions between the host and the microbiota that shape the intestinal environment $[5,6]$. Furthermore, dendritic cells (DCs) are pivotal in tolerance induction and direct the differentiation of $\mathrm{T}$ cells in the intestine. Therefore, DC apoptosis will result in immunosuppression, promote regulatory $\mathrm{T}$ cell (Treg) generation and induce functional impairment of remaining DCs [7,8]. Additionally, the gastrointestinal tract is continuously exposed to foreign antigens including invading bacteria and viruses, food antigens and also potentially altered-self antigens such as tumor antigens. Infection with certain bacteria and other pathogens can induce DC apoptosis, which will result in the dysregulation of the immune balance in the gastrointestinal tract [9]. Thus, deeper understanding of the mechanism regulating intestinal DC apoptosis is needed.

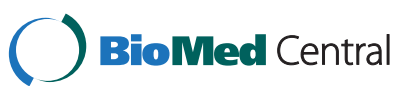

(c) 2014 Feng et al.; licensee BioMed Central Ltd. This is an Open Access article distributed under the terms of the Creative Commons Attribution License (http://creativecommons.org/licenses/by/2.0), which permits unrestricted use, distribution, and reproduction in any medium, provided the original work is properly credited. The Creative Commons Public Domain Dedication waiver (http://creativecommons.org/publicdomain/zero/1.0/) applies to the data made available in this article, unless otherwise stated. 
It has been shown that PI3K (phosphatidylinositol3-kinase)/AKT and MEK (MAP/ERK kinase)/ERK signaling is involved in the regulation of bone marrow-derived DC (BMDC) apoptosis, as inhibiting both PI3K and MEK resulted in $70 \%$ of the DCs undergoing apoptosis [10]. Furthermore, AKT (also known as protein kinase B, PKB) and ERK (Extracellular signal-regulated protein kinases) are known regulators of DC cell survival [11]. Additionally, it is also known Bax (Bcl-2 Associated X Protein) and Bcl-2 (B cell lymphoma/lewkmia-2) play a central role in regulating apoptosis [12]. Increased expression of Bcl-2 and decreased expression of Bax promotes cell survival by inhibiting apoptosis [13].

As far as we know, there are no reports on the effect of high glucose concentrations on DC apoptosis in the mouse intestine. We hypothesized that high concentrations of glucose might accelerate LPS (Lipopolysaccharides) induced DC apoptosis in the mouse intestine through alteration of the activation of ERK, AKT, Bax and $\mathrm{Bcl}-2$. We found that high glucose did indeed increase LPS-induced DC apoptosis. This effect was mediated through inhibition of AKT and ERK phosphorylation, increased Bax expression and decreased Bcl-2 expression. This study may give clues to understanding the mechanism behind the immunological changes present in the gut in diabetes mellitus.

\section{Methods}

\section{Experimental animals}

Male BALB/c mice, 10 weeks old, were purchased from the Animal Center at Shandong University. All experimental procedures were approved by and performed according to the guidelines of the animal ethics committee of the Shandong University School of Medicine. In brief, mice were injected intraperitoneally with streptozotocin $(\mathrm{STZ}, 60 \mu \mathrm{g} / \mathrm{g}$ ) once a day for 5 days to induce diabetes $[14,15]$. Control mice were injected with PBS (Phosphate buffer saline). Seven days after the final injection, blood glucose levels were examined by glucometer (UltraVue, Johnson \& Johnson, New Brunswick, NJ, USA). Mice with blood glucose levels greater than $300 \mathrm{mg} / \mathrm{dl}$ were considered diabetic. Diabetic mice were given LPS ( $1 \mathrm{mg}$ in $500 \mu \mathrm{L}$ PBS) orally once to induce inflammation on the 19th day after the first streptozotocin injection, while control mice were treated with the same volume of PBS. 24 hours later mice were killed and intestines dissected and digested with collagenase. Immune cells were isolated by layering on a Percoll gradient, then DCs were further purified using CD11c magnetic beads (130-052-001, Miltenyi Biotec Inc, Bergisch Gladbach, Germany) [16,17]. Finally the DCs were collected, stained and analyzed by flow cytometry.

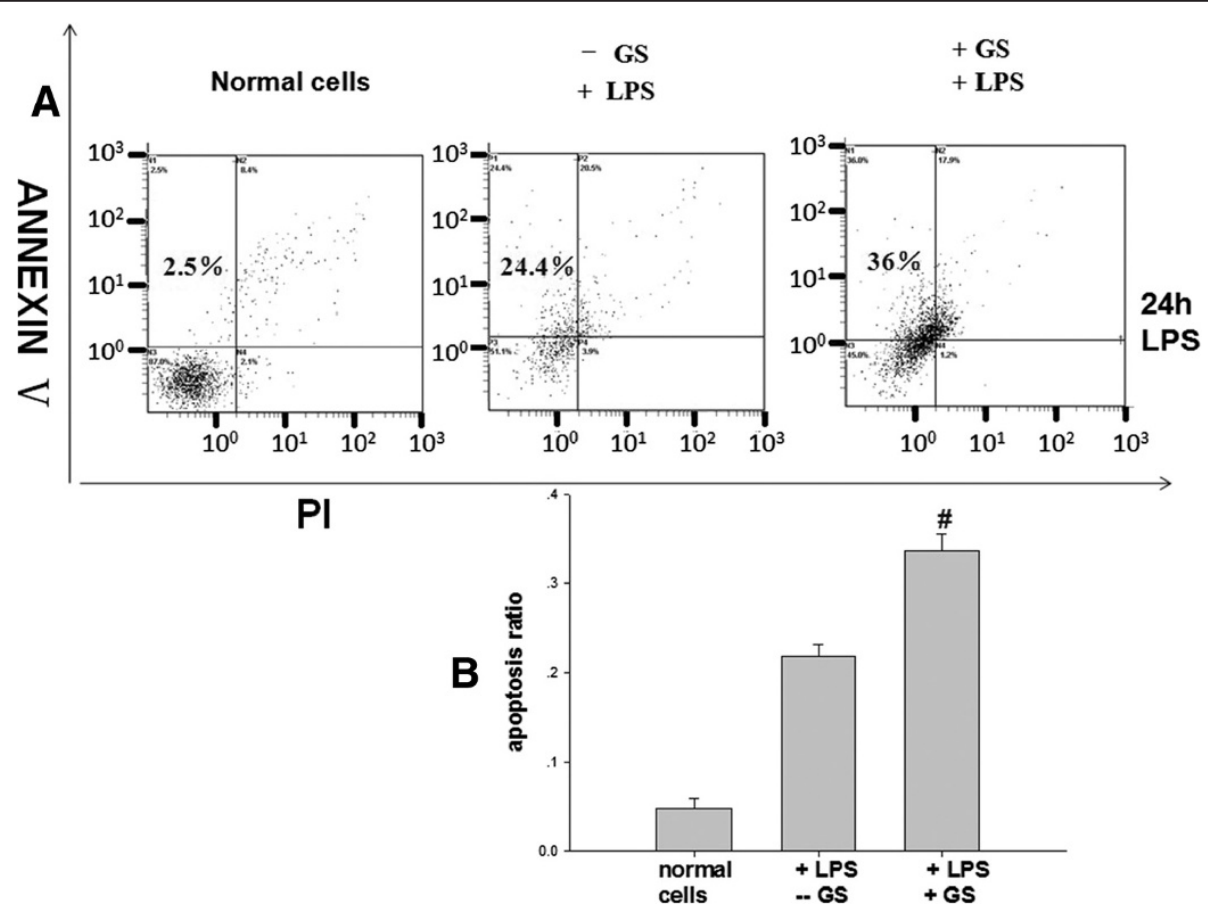

Figure 1 The effects of high glucose on LPS-induced dendritic cell apoptosis in mouse intestinal tract in vivo. (A) A representative FACS plot of intestinal DC apoptosis at $24 \mathrm{~h}$. The upper left quadrant represents the apoptotic cells (Annexin- $\mathrm{V}^{+}\left(\mathrm{An}^{+}\right) \mathrm{Pl}^{-}$); the lower left is live cells $\left(\mathrm{An}^{-} \mathrm{Pl}^{-}\right)$; the upper right is dead cells $\left(\mathrm{An}^{+} \mathrm{PI}^{+}\right)$. (B) Summary of intestinal DC apoptosis from mice administrated LPS $24 \mathrm{~h}$ previously. STZ treated mouse were used as the high glucose group. High glucose significantly increased apoptosis of intestinal DC, \#p $<0.05$ vs. control mice. 


\section{Cell culture}

Dendritic cells (DC2.4 cell line) were cultured on collagen coated dishes in complete medium containing RPMI-1640, $10 \%$ fetal bovine serum, $1 \times 10^{4}$ units $/ \mathrm{ml}$ penicillin and $10 \mathrm{mg} / \mathrm{ml}$ streptomycin. Cells were passaged using standard cell culture techniques. Culture dishes were placed in an incubator equilibrated with 5\% $\mathrm{CO}_{2}$ at $37^{\circ} \mathrm{C}$. The medium was refreshed at intervals of
3 days. To maintain uniform condition, the cells in passages 20 to 30 were used for experiments.

\section{Cell treatment}

DC2.4 cells were treated with a high dose of glucose $(25 \mathrm{mmol} / \mathrm{L})$ for $48 \mathrm{~h}$. Then LPS $(100 \mu \mathrm{g} / \mathrm{ml})$ was added to detect whether the glucose concentration could affect DC apoptosis. After 24 h LPS treatment (cells grown to
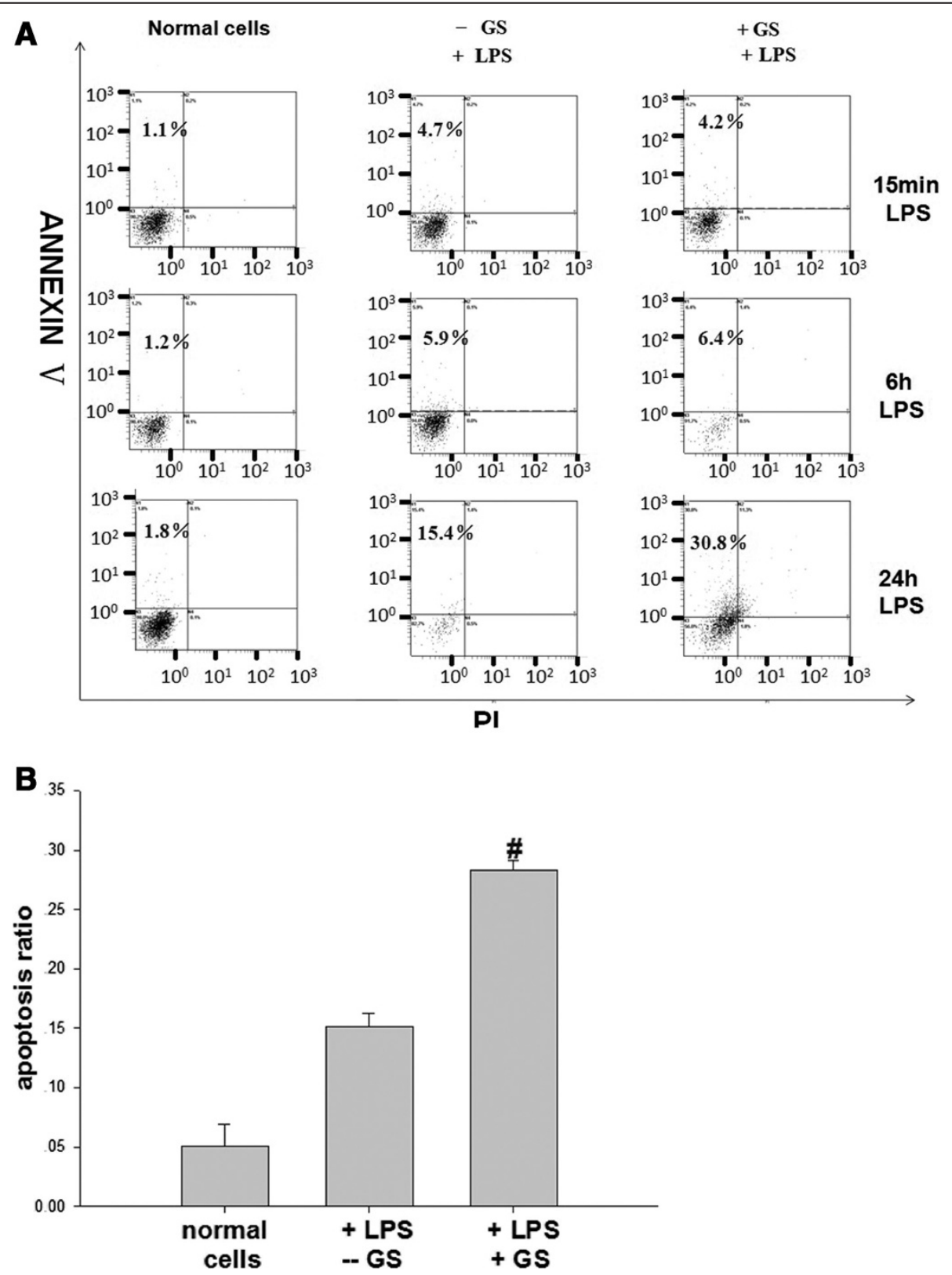

Figure 2 The effects of glucose on LPS-induced apoptosis in DC2.4 cells in vitro. (A) A representative figure of apoptosis induced by LPS treatment at $15 \mathrm{~min}, 6 \mathrm{~h}$ and $24 \mathrm{~h}$. (B) Histogram of the LPS-induced apoptosis of DC2.4 cells at $24 \mathrm{~h}$. Glucose pre-administration markedly elevated apoptosis of cells treated with LPS for $24 \mathrm{~h}$, but this effect was not evident in cells treated for only 15 min or 6 h, \#p<0.05 vs. control mice. 
approximately $80 \%$ confluence), the cells were harvested for both western blot analysis and flow cytometry.

\section{Analysis of apoptosis by flow cytometry}

Apoptosis of dendritic cells was determined using an Annexin-V and PI apoptosis kit (BU-ap0102, Life Technologies, Carlsbad, CA, USA). After washing twice with PBS, cells were re-suspended in binding buffer and incubated with Annexin-V and PI for 15 min. At least 5000 cells were counted per sample. Apoptotic cells appeared as Annexin- $\mathrm{V}$ positive and PI negative.

\section{Analysis of apoptosis by Hoechst 33258 staining} Hoechst 33258 staining (B33258, Sigma, St Loius, MO, USA) was used to visualize the morphological changes in apoptotic cell nuclei. After being washed with PBS and fixed with $4 \%$ paraformaldehyde for $30 \mathrm{~min}, 0.5 \mu \mathrm{g} / \mathrm{ml}$ Hoechst 33258 was added to the wells and incubated for $5 \mathrm{~min}$. Then cell nuclei were analyzed by fluorescence microscopy. Apoptotic cells were characterized by chromatin condensation and multiple chromatin fragments.

\section{Western blot}

Cells were collected and washed three times with PBS before lysis in lysis buffer (MK163780, ThermoFisher Scientific Inc, Waltham, MA, USA). The protein concentration of the lysates was determined according to the BCA method using the Protein Quantitative Analysis kit (2812 k; CWBIO, CoWin Biotech Co. Ltd., Beijing, China). For electrophoresis, $100 \mu \mathrm{g}$ of protein was loaded into the wells of a 10\% SDS polyacrylamide gel. After separation, proteins were transferred to nitrocellulose membranes, blocked for $3 \mathrm{~h}$ at room temperature in blocking buffer ( $5 \%$ nonfat dry milk, Tween-Tris-buffered saline), washed in PBS 3 times and incubated with primary antibody of ABCAM (Rabbit polyclonal to ERK, ab16869, 1: 1:5000; Rabbit polyclonal to AKT, ab66138, $0.15 \mu \mathrm{g} / \mathrm{ml}$; Rabbit polyclonal to Bax, ab7977, 1:1000; Rabbit polyclonal to Bcl-2, ab18210, $1 \mu \mathrm{g} / \mathrm{ml}$ ) and Actin (sc-1616, 1:200, SANTA CRUZ BIOTECHNOLOGY) overnight at $4^{\circ} \mathrm{C}$ with gentle agitation. Next day after washing three times in PBS, the nitrocellulose membranes were blotted for $1 \mathrm{~h}$ at room temperature with secondary antibodies (ab136817, 1:5000, abcam). Finally, immunolabeled protein bands were detected using the ECL(Electro-Chemi-

A

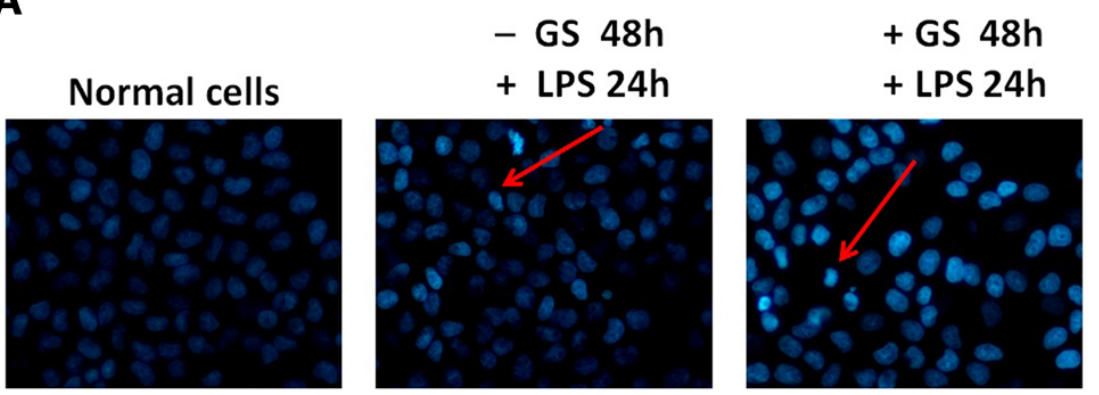

B

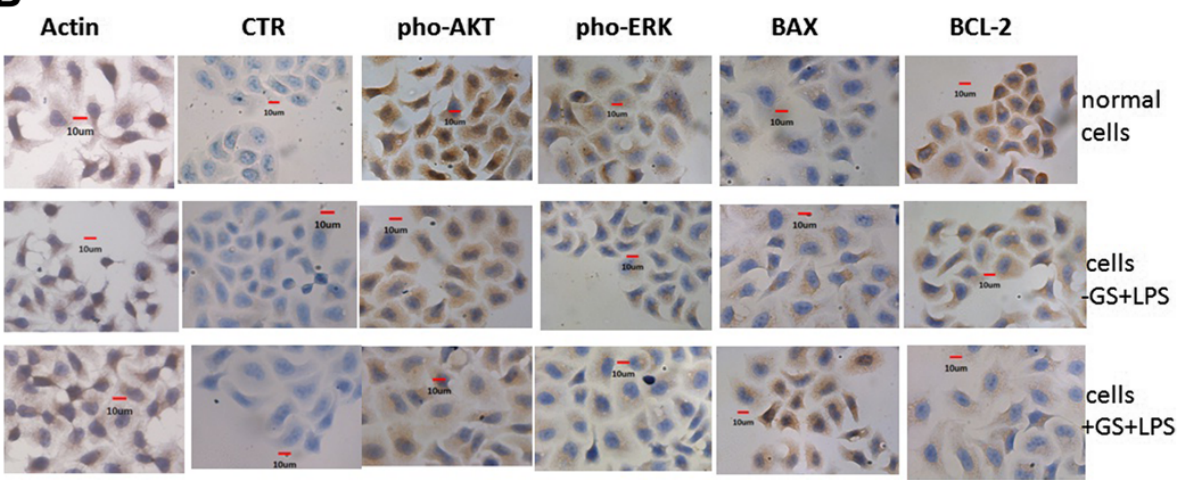

Figure 3 The effects of glucose on the nuclear morphology of LPS-treated DC2.4 cells in vitro. (A) Hoechst 33258 staining of DC2.4 cells treated with LPS for $24 \mathrm{~h}(400 \mathrm{x})$. Cells treated with a high concentration of glucose showed obvious apoptotic features including cytoplasm concentration, chromatin condensation and multiple chromatin fragments compared with cells without glucose. Brightly stained nuclei represent cells undergoing apoptosis. (B) Localization of AKT, ERK, Bax and BCl-2 in DCs (400X). CTR is negative control treated with the second antibody alone. No immunoreactive cells were detected in the CTR. Actin staining was used as positive control. High glucose elevated Bax expression but decreased the expression of $\mathrm{BCl}-2$ and the phosphorylation of AKT and ERK. 
Luminescence) method (Immobilon ${ }^{\text {TM }}$ Western, Millipore Corporation, Billerica, MA, USA) and quantified using an Alpha Imager 2200 (ProteinSimple, Santa Clara, CA, USA).

\section{Immunohistochemistry}

DC2.4 cells were treated as described above. After fixing in 4\% paraformaldehyde for $15 \mathrm{~min}$ and washing with PBS, cells were permeabilized with $0.1 \%$ triton X-100 for $15 \mathrm{~min}$. 3\% hydrogen peroxide was used to block endogenous peroxidases. After washing in PBS and blocking in $10 \%$ goat serum, cells were incubated with primary antibody of ABCAM (Rabbit polyclonal to ERK, ab16869, 1:1000; Rabbit polyclonal to AKT, ab66138, $1 \mu \mathrm{g} / \mathrm{ml}$; Rabbit polyclonal to Bax, ab7977, $1 \mu \mathrm{g} / \mathrm{ml}$; Rabbit polyclonal to Bcl-2, ab18210, $5 \mu \mathrm{g} / \mathrm{ml}$ ) and Actin (sc-1616, 1:250, SANTA CRUZ BIOTECHNOLOGY) overnight in a humidified chamber at $4^{\circ} \mathrm{C}$. The next day, the cells were washed before being incubated with secondary antibody (SP rabbit HRP kit, CW2035, CWBIO) for $30 \mathrm{~min}$ at room temperature. After washing, positive immunostaining was revealed by the $\mathrm{DAB}\left(3,3^{\prime}\right.$-diaminobenzidine) method (D8001, Sigma). PBS was used as a negative control for the primary antibodies and Actin was used as a positive control.

\section{Statistical analysis}

Data were analyzed with SigmaStat 3.5 software (SYSTAT Software, San Jose, CA, USA). One-way ANOVA analysis was followed by Dunnett's test to analyze the differences among the groups. Data are presented as the mean \pm SE of at least four independent experiments. $P<0.05$ was considered a statistically significant difference.

\section{Results}

Effects of glucose on LPS-treated dendritic cell apoptosis Untreated cells had a background level of less than 5\% apoptosis both in vivo and in vitro. In cells treated with LPS for $24 \mathrm{~h}$, glucose pre-administration markedly elevated the level of apoptosis (Figure 1 and Figure 2, $p<0.05$ ) while glucose alone had no statistically significant effect

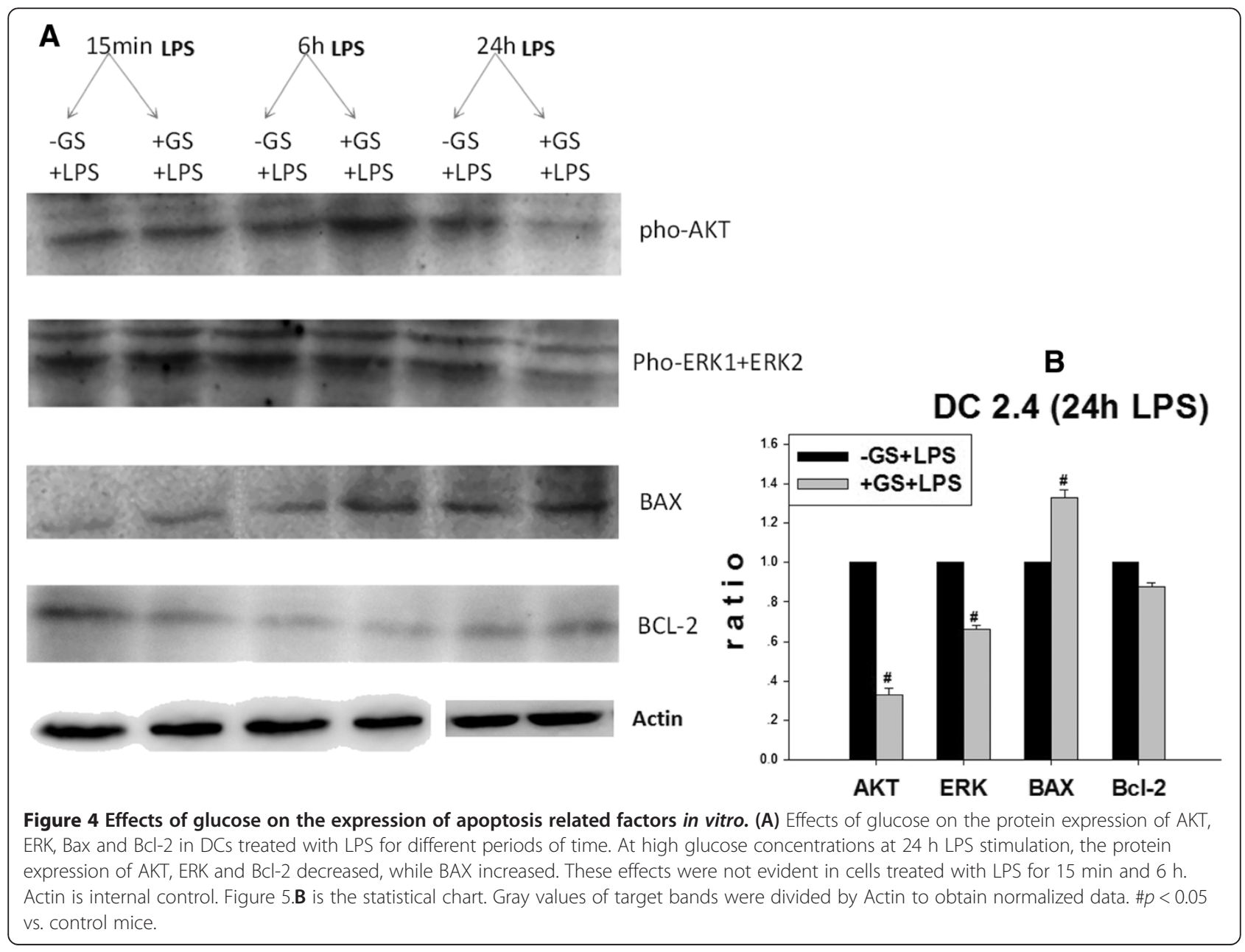


(data not shown). However, increased apoptosis was not evident at $15 \mathrm{~min}$ and $6 \mathrm{~h}$ in LPS treated cells (Figure 2A).

To determine the effects of glucose on apoptosis, cells were exposed to glucose for $48 \mathrm{~h}$. Then cell nuclei were stained using Hoechst 33258 and analyzed by fluorescence microscopy. As shown in Figure 3A, cells treated with glucose showed obvious apoptotic features including cytoplasm concentration, chromatin condensation and multiple chromatin fragments. In normal control cells, nuclei were distributed uniformly and were larger in size compared to the other two treated groups. As for these two treated groups, the cells pre-treated with glucose appeared to have a higher degree of apoptosis.

\section{Apoptosis related protein expression in dendritic cells}

As shown in Figure 4, glucose pre-administration could markedly reduce the levels of phosphorylated (pho)AKT, pho-ERK and Bcl-2 in cells treated with LPS for $24 \mathrm{~h}$ in vitro. However, these changes were not seen in the $15 \mathrm{~min}$ and $6 \mathrm{~h}$ treated groups. With regards to the expression of Bax, glucose could markedly elevate its expression in cells treated with LPS for $24 \mathrm{~h}$. In addition, similar effects were found in diabetic mouse in vivo that $\mathrm{AKT}$, pho-ERK and Bcl-2 were decreased and Bax was increased Figure 5. These results suggest that the increase in LPS-induced DC apoptosis in high glucose primed cells was mediated through AKT, ERK and $\mathrm{Bax} / \mathrm{Bcl}-2$ pathways.

\section{Location of apoptosis related proteins in dendritic cells}

The immunoreactivity for the apoptosis related proteins (AKT, ERK, Bax, Bcl-2) were mainly located in the cytoplasm (Figure 3B). The negative control showed no background staining. Glucose administration decreased the number of positive cells for the antiapoptotic proteins AKT, ERK and Bcl-2 and also reduced the intensity of immunoreactivity of the labeled cells. In comparison, both the number and intensity of the Bax immunoreactive cells was increased.

\section{Discussion}

The present study demonstrates that LPS-treated dendritic cells in the intestine of diabetic mice undergo increased apoptosis compared with normal mice. A similar effect was observed in the DC2.4 cell line in vitro. High glucose concentration increased the level of apoptosis of LPS-treated DCs via alterations in the AKT, ERK, Bax and $\mathrm{Bcl}-2$ pathways. AKT, ERK Bax and Bcl-2 were mainly located in the cytoplasm of DCs.

LPS, the prototypical endotoxin, is the major component of the outer membrane of Gram-negative bacteria and through TLR4 can trigger both proapoptotic and
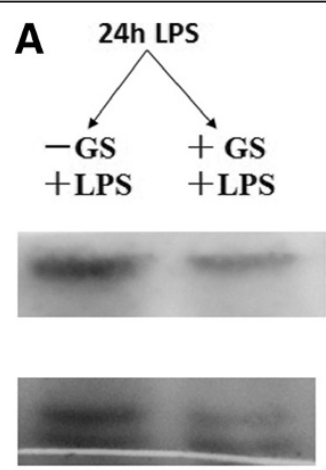

Pho-AKT

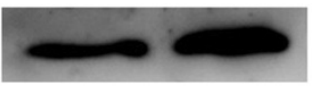

BAX

Pho-ERK1+ERK2

B

intestinal DC

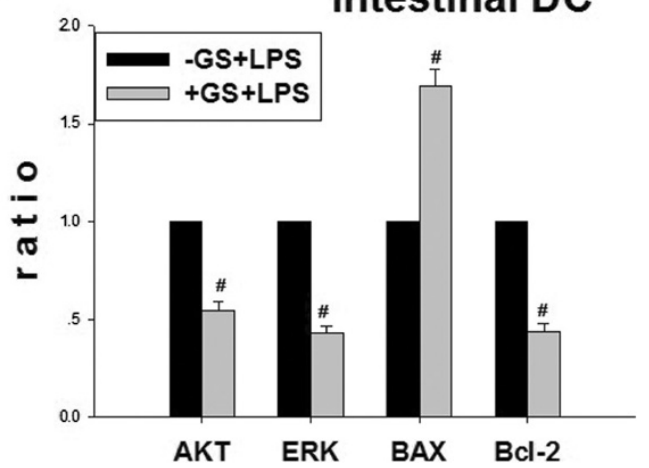

Figure $\mathbf{5}$ Effects of glucose on the expression of apoptosis related factors in vivo. Actin is internal control. High glucose could elevate intestinal DCs apoptosis of $24 \mathrm{~h}$ LPS treated diabetic mouse (Figure 5.A). Figure 5.B is the statistical chart. There was significant difference between the diabetic mouse and normal mouse. Gray values of target bands were divided by Actin to obtain normalized data. \# $p<0.05$ vs. control mice. 
antiapoptotic pathways [18]. LPS can induce PBMCderived DC apoptosis $[19,20]$, although other studies found no signs of apoptosis in LPS-treated DCs [21,22]. The Enterobacteriaceae are a large, heterogeneous group of gram-negative bacilli whose natural habitat is the intestinal tract of humans and animals. These bacteria will cause disease when the immune balance is disrupted. Therefore we used LPS to mimic the presence of bacteria in the intestine to explore if high glucose can affect DC survival in the inflamed intestine. We found that LPS could elevate intestinal DC apoptosis. Furthermore, LPS could also increase DC2.4 apoptosis in a dose-dependent fashion (data not shown).

AKT and ERK proteins are known regulators of cell survival. AKT, a serine/threonine-specific protein kinase, plays as a central role in the signaling pathways regulating metabolism and cellular transformation. AKT can regulate cell growth and apoptosis by activating a series of downstream signaling molecules [23]. It has been shown that DC maturation and antiapoptotic responses are associated with activation of AKT signaling. Blocking AKT signaling impairs DC maturation and induces apoptosis [24]. ERK is an important mediator of BMDC activation [25]. The Raf/MEK/ERK signaling pathway acts as an important element in DC generation and differentiation [10]. In the present study, we found that LPS decreased the phosphorylation of AKT and ERK1/2 in DCs at $24 \mathrm{~h}$. If the cells were pretreated with high glucose, there was a greater decrease in the phosphorylation of these survival factors.

The Bax/Bcl-2 family of proteins highlights the complexity of cellular biology. Bcl-2, an anti-apoptotic protein, is known to be a negative regulator of apoptosis which can prevent cytochrome c release from mitochondria and protect DNA from fragmentation. In cell culture, transfecting $\mathrm{Bcl}-2$ into U937 cells protected the cells from apoptosis induced by various insults [26]. Conversely Bax, a pro-apoptotic member of the Bax/Bcl-2 family, may be a key factor promoting cytochrome $\mathrm{c}$ release. The ratio of Bax to $\mathrm{Bcl}-2$ is therefore a crucial determinant of apoptosis in the cell. In the present study, it was demonstrated that LPS increased the expression of Bax protein and decreased the expression of $\mathrm{Bcl}-2$ protein in DCs at $24 \mathrm{~h}$. If the cells were pretreated with high glucose, the ratio of $\mathrm{Bax} / \mathrm{Bcl}-2$ was further increased.

\section{Conclusions}

Taken together, our results showed that high glucose levels present in diabetic mice could increase the LPSinduced apoptosis of DCs in the inflamed intestine. Apoptosis related proteins such as AKT, ERK, Bax and Bcl-2 regulated LPS-induced apoptosis in DCs. Specifically, high glucose concentrations increased LPS-induced apoptosis in DCs by enhancing the down-regulation of AKT and ERK phosphorylation and the up-regulation of the Bax/ Bcl-2 ratio. These results contribute to a greater understanding of the mechanism behind the immunological changes in the gastrointestinal tract of patients with diabetes mellitus.

\section{Abbreviations}

DC: Dendritic cell; LPS: Lipopolysaccharides; AKT: Serine/threonine protein kinase/known as Protein Kinase B; ERK: Extracellular signal-regulated protein kinases; Bax: Bcl-2 Associated X Protein; Bcl-2: B cell lymphoma/lewkmia-2.

\section{Competing interests}

The authors declare that they have no competing interests.

\section{Authors' contributions}

MF conceived and designed the experiments, carried out the experimental work and drafted the manuscript. $J$ carried out the flow cytometry and statistical analysis. JW took care of and obtained samples from mice. CM carried out protein detection and statistical analysis. YJ participated in analysis and interpretation of results. YW participated in analysis and interpretation of results. JZ contributed reagents and materials. QS performed data collection and statistical analysis. YJ contributed materials and drafted the manuscript. LG participated in paper design and coordination and helped to draft the manuscript. YZ participated in paper design and coordination and helped to draft the manuscript. All authors read and approved the final manuscript.

\section{Acknowledgments}

This project was supported by the Natural Scientific Foundation of China (No. 31100836 and No. 81000731) and Excellent Young and Middle-aged Scientists of Shandong Province (BS2012YY024).

\section{Author details}

${ }^{1}$ Central Laboratory, Shandong Provincial Hospital affiliated to Shandong University, Jinan, China. ${ }^{2}$ Department of Obstetrics and Gynecology, Shandong Provincial Hospital affiliated to Shandong University, Jinan, China. ${ }^{3}$ Jinan Central Hospital, Affiliated with Shandong University, Jinan, China. ${ }^{4}$ Department of Occupational Environmental Health Monitoring and Evaluation, Shandong Center for Disease Control and Prevention, Jinan, China. ${ }^{5}$ Department of Endocrinology, Shandong Provincial Hospital affiliated to Shandong University, Jinan, China. ${ }^{6}$ Department of Clinical Laboratory, Shandong Provincial Hospital affiliated to Shandong University, Jinan, China.

Received: 27 December 2013 Accepted: 14 May 2014

Published: 28 May 2014

\section{References}

1. Zhang P, Zhang X, Brown J, Vistisen D, Sicree R, Shaw J, Nichols G: Global healthcare expenditure on diabetes for 2010 and 2030. Diabetes Res Clin Pract 2010, 87(3):293-301.

2. Winer N, Sowers JR: Epidemiology of diabetes. J Clin Pharmacol 2004, 44(4):397-405

3. Otton $\mathrm{R}$, Soriano $\mathrm{FG}$, Verlengia $\mathrm{R}$, Curi R: Diabetes induces apoptosis in lymphocytes. J Endocrinol 2004, 182(1):145-156.

4. Noda T, Iwakiri R, Fujimoto K, Yoshida T, Utsumi H, Sakata H, Hisatomi A, Aw TY: Suppression of apoptosis is responsible for increased thickness of intestinal mucosa in streptozotocin-induced diabetic rats. Metabolism 2001, 50(3):259-264.

5. Izcue $A$, Coombes $J \mathrm{~L}$, Powrie F: Regulatory lymphocytes and intestinal inflammation. Annu Rev Immunol 2009, 27:313-338.

6. Linton L, Karlsson M, Grundstrom J, Hjalmarsson E, Lindberg A, Lindh $E_{\text {, }}$ Glise H, Befrits R, Janczewska I, Karlen P, Winqvist O, Eberhardson M: HLA-DR(hi) and CCR9 Define a Pro-Inflammatory Monocyte Subset in IBD. Clin Transl Gastroenterol 2012, 3:e29.

7. Kushwah R, Hu J: Dendritic cell apoptosis: regulation of tolerance versus immunity. J Immunol 2010, 185(2):795-802.

8. Ng SC, Benjamin JL, McCarthy NE, Hedin CR, Koutsoumpas A, Plamondon S, Price CL, Hart AL, Kamm MA, Forbes A, Knight SC, Lindsay JO, Whelan K, Stagg AJ: Relationship between human intestinal dendritic cells, gut 
microbiota, and disease activity in Crohn's disease. Inflamm Bowel Dis 2011, 17(10):2027-2037.

9. Arranz E, Pena AS, Bernardo D: Mediators of inflammation and immune responses in the human gastrointestinal tract. Mediators Inflamm 2013, 865638

10. Xie J, Qian J, Yang J, Wang S, Freeman ME 3rd, Yi Q: Critical roles of Raf/ MEK/ERK and PI3K/AKT signaling and inactivation of p38 MAP kinase in the differentiation and survival of monocyte-derived immature dendritic cells. Exp Hematol 2005, 33(5):564-572.

11. Schafer M, Koppe F, Stenger B, Brochhausen C, Schmidt A, Steinritz D, Thiermann H, Kirkpatrick CJ, Pohl C: Influence of organophosphate poisoning on human dendritic cells. Chem Biol Interact 2013, 206(3):472-478.

12. Nogueira CV, Lindsten $T$, Jamieson $A M$, Case CL, Shin S, Thompson CB, Roy CR: Rapid pathogen-induced apoptosis: a mechanism used by dendritic cells to limit intracellular replication of Legionella pneumophila. PLoS Pathog 2009, 5(6):e1000478.

13. Chung J, Yoon YO, Lee JS, Ha TK, Ryu SM, Kim KH, Jeong MH, Yoon TR, Kim HK: Inulin induces dendritic cells apoptosis through the caspasedependent pathway and mitochondrial dysfunction. Biol Pharm Bull 2011, 34(4):495-500.

14. Chen WB, Gao L, Weiland M, Zhao J, Liu M, Zhou L, Mi QS: Deletion of miRNAs in bone marrow prevents streptozotocin-induced murine autoimmune diabetes but deletion of miR-155 does not. Cell Cycle, 12(7):1151-1152

15. Motyl K, McCabe LR: Streptozotocin, type I diabetes severity and bone. Biol Proced Online 2009, 11:296-315.

16. Chirdo FG, Millington OR, Beacock-Sharp H, Mowat AM: Immunomodulatory dendritic cells in intestinal lamina propria. Eur J Immunol 2005, 35(6):1831-1840.

17. Geem D, Medina-Contreras O, Kim W, Huang CS, Denning TL: Isolation and characterization of dendritic cells and macrophages from the mouse intestine. J Vis Exp, (63):e4040.

18. Lombardo E, Alvarez-Barrientos A, Maroto B, Bosca L, Knaus UG: TLR4-mediated survival of macrophages is MyD88 dependent and requires TNF-alpha autocrine signalling. J Immunol 2007, 178(6):3731-3739.

19. Handley ME, Thakker M, Pollara G, Chain BM, Katz DR: JNK activation limits dendritic cell maturation in response to reactive oxygen species by the induction of apoptosis. Free Radic Biol Med 2005, 38(12):1637-1652.

20. Yen JH, Ganea D: Interferon beta induces mature dendritic cell apoptosis through caspase-11/caspase-3 activation. Blood 2009, 114(7):1344-1354.

21. Nakaya K, Nabata Y, Ichiyanagi T, An WW: Stimulation of dendritic cell maturation and induction of apoptosis in leukemia cells by a heat-stable extract from azuki bean (Vigna angularis), a promising immunopotentiating food and dietary supplement for cancer prevention. Asian Pac $J$ Cancer Prev 2012, 13(2):607-611.

22. Zhang H, Jiao Q, Gong $Q$, Zhang Y, Zhang W, Hu Z: Baicalin induced dendritic cell apoptosis in vitro. Frontiers in pharmacology 2011, 2:15.

23. Zhang Y, Wang X, Yang H, Liu H, Lu Y, Han L, Liu G: Kinase AKT controls innate immune cell development and function. Immunology 2013, 140(2):143-152.

24. Stefanidou M, Ramos I, Mas Casullo V, Trepanier JB, Rosenbaum S, Fernandez-Sesma A, Herold BC: Herpes simplex virus 2 (HSV-2) prevents dendritic cell maturation, induces apoptosis, and triggers release of proinflammatory cytokines: potential links to HSV-HIV synergy. J Virol, 87(3):1443-1453.

25. Srivastava RM, Varalakshmi C, Khar A: The ischemia-responsive protein 94 (Irp94) activates dendritic cells through NK cell receptor protein-2/NK group 2 member D (NKR-P2/NKG2D) leading to their maturation. J Immunol 2008, 180(2):1117-1130.

26. Teicher BA: Molecular targets and cancer therapeutics: discovery, development and clinical validation. Drug Resist Updat 2000, 3(2):67-73.

doi:10.1186/1471-230X-14-98

Cite this article as: Feng et al:: High glucose increases LPS-induced DC apoptosis through modulation of ERK1/2, AKT and Bax/BCl-2. BMC Gastroenterology 2014 14:98.

\section{Submit your next manuscript to BioMed Central and take full advantage of:}

- Convenient online submission

- Thorough peer review

- No space constraints or color figure charges

- Immediate publication on acceptance

- Inclusion in PubMed, CAS, Scopus and Google Scholar

- Research which is freely available for redistribution

Submit your manuscript at www.biomedcentral.com/submit
C Biomed Central 